\title{
LOS CENTROS DE ATENCIÓN TEMPORAL DE EXTRANJEROS COMO NUEVO MODELO DE CONTROL MIGRATORIO: SITUACIÓN ACTUAL, (DES)REGULACIÓN JURÍDICA Y MECANISMOS DE CONTROL DE DERECHOS Y GARANTÍAS*
}

\author{
THE FOREIGNERS'TEMPORARY STAY CENTRES \\ AS THE NEWMODEL OF MIGRATION CONTROL: \\ CURRENT SITUATION, LEGAL (DE)REGULATION \\ AND MECHANISMS OF CONTROL AND GUARANTEE OF RIGHTS
}

\author{
IKER BARBERO** \\ Universidad del País Vasco \\ Euskal Herriko Unibertsitatea
}

Fecha de recepción: $17-1-20$

Fecha de aceptación: 10-6-20

Resumen: En los últimos años, con el incremento de rescates y llegadas a costas europeas por vías marítimas de personas migrantes se ha producido un cambio en el modelo de contención. En el caso concreto del Estado español, si anteriormente eran los Centros de Internamiento para Extranjeros (CIE) o los Centros de Estancia Temporal para Inmigrantes (CETI) los dispositivos para la gestión de las llegadas y derivación hacia otros procedimientos de extranjería, en la actualidad, siguiendo la lógica humanitaria-gerencial del control de fronteras, se han creado de facto los denominados Centros de Atención Temporal de Extranjeros o CATE. Se trata de edificios o recintos vallados en zonas portuarias donde se mantiene detenidas a las personas durante un máximo de 72 horas para proceder a su reseña policial y atención humanitaria. En este artículo se argu-

* Este artículo se enmarca dentro del proyecto de investigación Universidad-Sociedad “TRANSITEUS: La acogida de migrantes en tránsito en el País Vasco/Euskadi: diagnóstico y propuestas desde una perspectiva garantista" (US 19/08). www.transiteus.eus.

** Profesor Agregado del Departamento de Derecho Administrativo, Constitucional y Filosofía del Derecho de la Universidad del País Vasco-Euskal Herriko Unibertsitatea. Iker. barbero@ehu.eus

ISSN: 1133-0937

DOI: https://doi.org/10.20318/dyl.2021.6108

DERECHOS Y LIBERTADES

Número 45, Época II, junio 2021, pp. 267-302 
mentará que la ausencia de una regulación legal de estos centros, además de añadir inseguridad jurídica a las actuaciones del personal de la Administración pública, dificulta el reconocimiento derechos fundamentales de las personas en ellos recluidas y omite mecanismos de control imprescindibles propios de una sociedad democrática.

Abstract: In recent years, due to the increase of rescues and coastal arrivals of migrants there has been a change in the containment model. If previously it were the Foreigners' Detention Centres (or CIE) or the Immigrants' Temporary Stay Centres (or CETI) the ordinary devices for managing arrivals and referral to other immigration procedures, at present, following the humanitarian-managerial logic of border control, the so-called Foreigners' Temporary Stay Centres have been created de facto. These are fenced buildings or seals in port areas where people are kept for a maximum of 72 hours to proceed to their police proceedings. This article will argue that the absence of a legal regulation of these centers, in addition to adding legal insecurity to the actions of public administration personnel, makes it difficult to recognize fundamental rights of the people detained and omits control mechanisms essential in any democratic society.

Palabras clave: Centros de Atención Temporal de Extranjeros, control migratorio, fronteras, derechos fundamentales, mecanismos de garantía

Keywords: Foreigners' Temporary Stay Centres, migration control, borders, fundamental rights, guarantee mechanisms

\section{INTRODUCCIÓN}

El año 2018 será, sin duda, una fecha de referencia en el estudio de control fronterizo y de los mecanismos de contención ante las llegadas a costas españolas de embarcaciones de migrantes procedentes del norte de África (principalmente Marruecos y África Subsahariana). Según los datos recopilados por la Organización Internacional para las Migraciones (OIM) hasta el 28 de diciembre de 2018, 56.480 personas lograron llegar a España tras cruzar el mar Mediterráneo (y al menos 769 migrantes perdieron la vida o desaparecieron), más personas que en los últimos siete años juntos, e incluso superando las cifras registradas durante la «crisis de los cayucos〉 de 2006, cuando llegaron 39.180. Esto supuso una verdadera situación de crisis humanitaria en la que la gestión de la recepción de los y las migrantes se produjo, y sigue produciéndose, no en clave de rescate humanitario, sino principalmente de control policial de fronteras y, la mayoría de las veces, fruto de la improvisación, lo que en numerosas ocasiones supone una flagrante vulneración de derechos fundamentales. 
Dentro de las distintas experiencias improvisadas es preciso recordar el caso del Centro de Archidona (oficialmente denominado Centro Penitenciario Málaga II), donde en noviembre de 2017, se internó a 576 ciudadanos argelinos y uno marroquí, tras haber permanecido horas detenidos en tiendas de campaña en la dársena del Puerto de Cartagena a la espera de las resoluciones de los juzgados de instrucción de Murcia, Valencia o Andalucía que decretasen, tal y como prevé la Ley de Extranjería, el internamiento en Centro de Internamiento para Extranjeros (CIE $)^{1}$. Lo relevante del caso es que se no se trataba de un CIE preexistente como los de Madrid, Barcelona, Murcia, Canarias, Valencia o Algeciras, sino que se trataba de un centro penitenciario ya decretado como tal por orden ministerial ${ }^{2}$, pero sin inaugurar, que por decisión del entonces Ministro del Interior, Juan Ignacio Zoido, adquirió el carácter de $\mathrm{CIE}^{3}$ (aparentemente dependiente del CIE de Málaga cerrado en 2013), y considerado como "un centro desconocido" en los propios autos de los jueces de instrucción de Vera (Almería) y Lorca (Murcia), encargados de autorizar el internamiento. Por un lado, es importante señalar que, según la Ley de Extranjería y la doctrina del Tribunal Constitucional STC de 7 de julio de 1987, los CIE en España son centros de carácter "no penitenciario" 4 . Y, por otro lado, también es necesario recordar que el 29 de diciembre, un ciudadano argelino apareció ahorcado en una celda en la

1 Ver la Declaracion del Defensor del Pueblo al respecto el 1 de diciembre de 2017 “El Defensor detecta numerosas carencias en las instalaciones de Archidona"; disponible en www. defensordelpueblo.es/noticias/instalaciones-archidona; ElDiario.es "Archidona: un CIE en "fraude de ley" y una actuación policial “violenta”, 13 de junio de 2018.

2 Orden INT/247/2017, de 16 de marzo, por la que se crea el Centro Penitenciario de Málaga II, en Archidona (Málaga). Disponible en https://www.boe.es/boe/dias/2017/03/18/pdfs/ BOE-A-2017-3013.pdf

3 Si bien el Defensor del Pueblo solicitó información a la Dirección General de Policía (Ministerio del Interior) acerca del dictado de la orden preceptiva, y su correspondiente publicación en boletín oficial, a la que hace referencia el artículo 5 mencionado, la DGP informó que el ministro, el día 19 de noviembre de 2017, «dictó Resolución por la que se habilitan las instalaciones del Centro penitenciario Málaga II en Archidona (Málaga) como centro de ingreso provisional de extranjeros». En opinión del Defensor del Pueblo, al no haber sido publicada en el BOE, no se perfeccionó su eficacia jurídica, por tanto, el CIE adolecería de nulidad de pleno Derecho. DEFENSOR DEL PUEBLO. Informe Anual 2017. Mecanismo Nacional de Prevención, p 87 y ss.

4 A. SOLANES, “Un análisis crítico de los centros de internamiento de extranjeros en España: normativa, realidad y alternativas. Revista Telemática de Filosofía del Derecho, núm. 19, 2016, pp. 37-76; A. JARRIN MORÁN; D. RODRIGUEZ; J. DE LUCAS, “Los Centros de Internamiento para Extranjeros en España: una evaluación crítica". Revista CIDOB d'afers internacionals, 2012, pp. 201-220. 
que había sido aislado, sin que se pudiera aclarar las circunstancias de la muerte ya que el juez archivó de manera acelerada la causa y los posibles testigos fueron expulsados. El 10 de enero del 2018 el Ministerio de Interior cerró Archidona, enviando a los que aún permanecían recluidos a los CIE de Madrid y Barcelona.

Así, durante los meses posteriores, desde instancias gubernamentales, se optó por alquilar o pedir la cesión de polideportivos, lonjas y almacenes en desuso o instalaciones destinadas a grandes eventos para albergar a cientos de personas recién llegadas mientras se procedía a la reseña policial (toma de huellas, inclusión en bases de datos como EURODAC, filiación y apertura de expedientes de devolución, principalmente). Ante esta saturación de los dispositivos de primera recepción durante el verano de 2018, ocurrieron situaciones tan extremas como cuando casi 400 personas permanecieron custodiadas durante cinco días a bordo del buque de Salvamento Marítimo "María Zambrano", amarrado en el Puerto de Algeciras. Tal y como constató el Defensor del Pueblo en la inspección que realizó el último día que se le dio tal uso, "la embarcación no reunía las más elementales condiciones como lugar de acogida, las personas retenidas a bordo no fueron formalmente recibidas por la Policía Nacional durante ese período de tiempo para que no comenzara a computarse el plazo máximo de 72 horas de una detención, privando a las personas de los derechos más elementales hasta que fueron trasladadas a otros dispositivos de atención y custodia" (visita 65/2018) 5 .

Este hecho precisamente nos lleva a la reflexión principal de este artículo: tanto por una lógica de gestión más eficaz de las llegadas como por la presión que colectivos sociales y algunas instituciones de garantías de derechos ejercieron durante 2018, las autoridades gubernamentales han optado por un cambio de estrategia para la contención de migrantes rescatados en el mar o llegados en embarcaciones por puestos no habilitados. Si bien antes su gestión se realizaba mediante el internamiento en los distintos CIE dispersos por todo el territorio estatal, o bien a través de los Centros de Estancia Temporal para Inmigrantes (CETI) de Ceuta y Melilla ${ }^{6}$, el colapso de estos dos tipos de centros tanto por el alto número de llegadas como por el esfuer-

5 DEFENSOR DEL PUEBLO. Ficha de seguimiento de la visita realizada por el MNP. 2018. Disponible en www.defensordelpueblo.es/gestionDocumentalWS/rest/ matrizSeguimientoMNP/18012926

6 Los CETI son centros dependientes del Ministerio de Migración, Trabajo y Seguridad Social creados en 1999 (Melilla) y 2000 (Ceuta), concebidos como dispositivos de primera acogida provisional y destinados a dar servicios y prestaciones sociales básicas a migrantes y 
zo burocrático y temporal que supone decretar el internamiento en CIE o aliviar los CETI, ha motivado a la creación de facto, es decir, sin norma jurídica concreta alguna, de unos nuevos dispositivos de contención denominados Centros de Atención Temporal de Extranjeros o CATE (en años anteriores, como 2017 y principios del 2018, han recibido la denominación de Centros de Primera Asistencia y Detención de Extranjeros, por el Defensor del Pueblo77).

Aunque en las siguientes partes de este texto, mediante el análisis normativo, los datos estadísticos y la revisión bibliográfica, profundizaremos en cuestiones como su localización, regulación jurídica, vulneración de derechos y mecanismos de control, podemos adelantar una definición diciendo que son centros ubicados en las inmediaciones portuarias donde las personas rescatadas o interceptadas en el mar son desembarcadas directamente a unos recintos vallados, conformados por módulos prefabricados, y donde permanecerán detenidas durante un periodo máximo de 72 horas para que agentes de la Policía Nacional española (y Frontex) procedan a la identificación e investigación policial, y donde determinadas entidades procuran una serie de servicios como la atención médica y acogida (Cruz Roja), información sobre protección internacional (ACNUR/CEAR) y asistencia letrada (los turnos de extranjería de los Colegios de Abogacía). Precisamente, merece ser problematizada su denominación actual "de acogida", en tanto que desaparece el anterior apelativo de "centros de detención" ¿Son realmente centros de acogida? ¿Responde esta acogida a criterios de dignidad o humanidad? Como veremos a continuación, desde un punto de vista propio, se trata de una tendencia europea/global destinada a instaurar y legitimar un nuevo régimen de contención policial en los rescates en fronteras.

\section{LA CREACIÓN DE CENTROS DE RECEPCIÓN EN EL CONTEXTO EUROPEO DE EMERGENCIA HUMANITARIA}

La Unión Europea (sus instituciones y sus Estados miembros) actualmente se enfrentan al mayor desafío en materia de inmigración y asilo. Las

demandantes de protección internacional llegados a estas ciudades autónomas mientras realizan los trámites de identificación y chequeo médico antes de ser trasladados a la península.

DEFENSOR DEL PUEBLO. Ficha de seguimiento de la visita realizada por el MNP. 2017. Disponible en https://www.defensordelpueblo.es/evento-mnp/centro-primera-asistenciadetencion-extranjeros-motril-granada/

DEFENSOR DEL PUEBLO. Ficha de seguimiento de la visita realizada por el MNP. 2017. Disponible en https://www.defensordelpueblo.es/evento-mnp/centro-de-primera-asistenciay-detencion-de-extranjeros-en-adeje-santa-cruz-de-tenerife/

ISSN: 1133-0937

DOI: https://doi.org/10.20318/dyl.2021.6108
DERECHOS Y LIBERTADES

Número 45, Época II, junio 2021, pp. 267-302 
tendencias actuales están poniendo en cuestión el modelo europeo de gestión de fronteras primeramente en las externas, principalmente en Grecia, Italia, Malta y España; como posteriormente en las fronteras internas, con el restablecimiento de controles internos para detener los movimientos secundarios en Ventimiglia, Hendaia o Calais ${ }^{8}$. En definitiva, el propio sistema Schengen está en cuestión. Por este motivo precisamente, para buscar figuras semejantes a los CATE en el panorama internacional, debemos partir de cómo son los centros de recepción para la identificación ante llegadas marítimas diseñados por la Unión Europea. Por tanto, se trataría de una figura similar a lo que en terminología técnica se han denominado "Hotspots". El 13 de abril de 2015, a través de la Agenda Europea de Migración", la Comisión Europea proponía una serie de mecanismos de la UE para actuar "en caso de que uno o más Estados miembros se enfrenten a una situación de emergencia caracterizada por una afluencia repentina de nacionales de terceros países (artículo 78 (3) del Tratado de Funcionamiento de la UE)". Entre los mecanismos propuestos destacaba la aproximación de puntos críticos o "Hotspots approach", consistente en el apoyo operativo en la provisión de necesidades iniciales en la recepción, identificación, registro y toma de huellas de los solicitantes de asilo para su posterior reubicación entre los Estados Miembros ${ }^{10}$. El origen de esta propuesta residía, de un lado, en la demanda por parte de Estados miembros como Francia y Alemania aquejados de la llegada de los denominados "movimientos secundarios", principalmente migrantes irregulares y demandantes de asilo procedentes de Italia y Grecia, y, por otro lado, de las autoridades de estos últimos Estados que demandaban apoyo comunitario en la tarea de contención e identificación. A este respecto, fue significativo el incidente ocurrido en 2011 entre Francia e Italia cuando cientos de tunecinos cruzaron la frontera por Ventimiglia con permisos de re-

8 I. BARBERO y G. DONADIO, “La externalización interna de las fronteras en el control migratorio en la UE". Revista CIDOB d'Afers Internacionals, núm. 122, 2019, pp. 137-162.

9 COMISION EUROPEA, Comunicación de la Comisión al Parlamento, a Consejo, al Comité Económico y Social y al Comité de las Regiones. Una Agenda Europea de Migración. COM/2015/0240 final https://eur-lex.europa.eu/legal-content/ES/TXT/PDF/?uri=CELEX:52015D C0240Efrom $=E N$

10 M. TAZZIOLI y G. GARELLI, "Containment beyond detention: The hotspot system and disrupted migration movements across Europe". Environment and Planning D: Society and Space, 2018, Versión en línea disponible en https://journals.sagepub.com/ doi/10.1177/0263775818759335 
sidencia temporales emitidos por las autoridades italianas ${ }^{11}$. Según Vradis et al, en cierto modo, los hotspots, junto con la renovación de Frontex y el esquema de reubicación, suponen la culminación de la Comisión Juncker de "europeizar la frontera", es decir, considerar las fronteras exteriores como un asunto del que deben hacerse cargo tanto las Instituciones europeas como todos sus Estados Miembros ${ }^{12}$.

Este planteamiento político del "hotspot" se ha traducido en la apertura oficial de centros de primera recepción o hotspots en el Sur de Italia (Lampedusa, Messina, Pozzallo, Taranto y Trapani) y las Islas Griegas (Chios, Kos, Leros, Lesvos y Samos). Son centros donde personal de agencias europeas como Frontex (la Agencia Europea de Fronteras y Guardacostas), EASO (la Agencia Europea de Asistencia al Asilo), Europol (la Agencia Europea de Cooperación Policial), Eu-LISA (Agencia Europea para la Gestión Operativa de Sistemas Informáticos de Gran Magnitud en el Espacio de Libertad, Seguridad y Justicia) y Eurojust (la agencia de Cooperación Judicial), prestan asistencia a la autoridades nacionales en el registro, y clasificación de las personas recién llegadas, la investigación de redes de tráfico de personas y otras actividades criminales, así como en las entrevistas a solicitantes de protección internacional ${ }^{13}$. En definitiva, se trata de contener a las personas el tiempo suficiente para proceder a su identificación con el fin de que, en caso de que formulen solicitudes de protección internacional en Estado Miembros distintos a Italia o Grecia ${ }^{14}$, sean retornadas a estos Estados pues

11 E. PISTOIA, "Il muro invisibile ma impervio di Ventimiglia". Federalismi.it Rivista di diritto pubblico italiano, comparato, europeo, núm., 3, 2018, p. 1-16. G. DONADIO, "The Irregular Border: Theory and Praxis at the Border of Ventimiglia in the Schengen Age" en L. AMIGONI, S. ARUIVAN BONNIN, G. PROGLIO, C. VERGNANO (eds) Debordering Europe Migration and Control Across the Ventimiglia Region, Routledge, Londres, pp. 109-133.

12 A. VRADIS, E. PAPADA, J. PAINTER y A. PAPOUTSI, New borders: hotspots and the European migration regime, London: Pluto Press, 2019.

13 Concretamente, Europol se encarga de proporcionar asistencia técnica en la comprobación de documentos de identificación, y Frontex, a través de los denominados "equipos de interrogación conjunta (Joint Screening Team) realiza interrogatorios para identificar redes y rutas migratorias para sus informes de análisis de riesgos y también participa en dispositivos de asistencia al retorno de migrantes irregulares y demandantes de asilo cuyas solicitudes han sido rechazadas. EuLISA proporciona asistencia técnica en la operacionalización e introducción de datos en la base EURODAC para el registro de datos biométricos de demandantes de asilo y migrantes que hayan cruzado de manera irregular las fronteras exteriores de la UE.

14 Siguiendo las pautas de los formularios que se les entrega en Grecia (disponible en https://www.easo.europa.eu/sites/default/files/public/BZ0116194ENN_0.pdf) y en Italia (disponible en https://www.easo.europa.eu/sites/default/files/public/BZ0416141ENC_proof2_5rev.pdf).

ISSN: 1133-0937

DOI: https://doi.org/10.20318/dyl.2021.6108
DERECHOS Y LIBERTADES

Número 45, Época II, junio 2021, pp. 267-302 
al ser los lugares de entrada en la UE, son, en aplicación del Reglamento de Dublín (N 604/2013), formalmente los responsables de la tramitación de las demandas de asilo.

Desde una perspectiva académica crítica, Giuseppe Campesi ${ }^{15}$ ubica estos centros de recepción dentro del análisis del proceso de progresiva institucionalización de las distintas lógicas securitarias que están siendo implementadas en la Unión Europea ${ }^{16}$. Según Campesi, en el caso italiano, mientras que los centros de internamiento previo a la deportación son gobernados por la lógica de gestión del riesgo ${ }^{17}$, estos centros de primera acogida son operados por la ambigua lógica de funcionamiento de "gobierno humanitario" como mecanismo de control ${ }^{18}$. Dice Walters a este respecto que en espacios fronterizos ubicados en el Mediterráneo como Lampedusa, pero también en muchos otros lugares del mundo, confluyen juntas "en una incómoda alianza, la política de alienación con la política del cuidado, y una táctica de abyección con una de recepción" ${ }^{19}$. Y es que cruzar la frontera, ya sea terrestre o marítima, se ha convertido en una opción peligrosa debido a la securitización, militarización y privatización de su control ${ }^{20}$, siendo expresión de esta idea la reciente operación EUNAVFOR MED SOPHIA (desde 2015) ${ }^{21}$, coordinada por Frontex y Europol, y ejecutada por fuerzas policiales y militares de los Estados Miembro, "con el fin de interrumpir el negocio de las redes de contrabando y tráfico de personas en la zona sur del Mediterráneo Central" (Decisión 2015/778 de 18 de mayo de 2015). De ahí que se busque

15 G. CAMPESI, "Between containment, confinement and dispersal: the evolution of the Italian reception system before and after the "refugee crisis", Journal of Modern Italian Studies, núm 23 vol. 4, 2018, pp 494-506

16 J. HUYSMANS, The politics of insecurity: Fear, migration and asylum in the EU. Routledge, 2006; L.A. DE VRIES; E. GUILD; S. CARRERA, Documenting the Migration Crisis in the Mediterranean Spaces of Transit, Migration Management and Migrant Agency. CEPS Liberty and Security in Europe No. 94 2016. 2016; E. GUILD, Controlling frontiers: free movement into and within Europe. Routledge, 2017.

17 A. DE GIORGI, Tolerancia cero. Estrategias y prácticas de la sociedad de control. Barcelona, Virus, 2005.

18 M. AGIER, Gérer les indésirables. Des camps de réfugiés au gouvernement humanitaire. Flammarion, 2008.

19 W. WALTERS, "Foucault and frontiers: Notes on the birth of the humanitarian border." U. BRÖCKLING, S. KRASMANN \& Th. LEMKE (eds.), Governmentality: Current Issues and Future Challenges. Routledge. 2010, pp. 138--164.

20 DRIFTE, Reinhard. Migrants, human security and military security. En Migration, Regional Integration and Human Security. Routledge, 2017, p. 113-130.

21 Disponible en https://www.operationsophia.eu/ 
cierta legitimidad "humanizando" las fronteras con el empleo de tecnologías de anticipación en la detección y la presencia de organizaciones no gubernamentales que, en virtud de fondos y concesiones públicas, al tiempo que palian el sufrimiento consecuencia del tortuoso viaje y durante la detención, en cierta manera, pasan a ser parte de la denominada "industria neoliberal de las migraciones" 22 .

Con todo, más allá de políticas y acciones de caridad a las que se refiere Walter, otro elemento al que hay que prestar atención es la situación de excepción jurídica provocada por la consideración de emergencia y las consecuencias que ésta tiene sobre los derechos y garantía de los migrantes recluidos en estos centros ${ }^{23}$. Si bien en el ordenamiento comunitario, así como en gran parte de los Estados miembros se prevén regulaciones de estos centros así como mecanismos formales para el control de la detención ante autoridades administrativas y judiciales ${ }^{24}$, esos mecanismos de queja y reparación, en momento de emergencia, suelen ser insuficientes por su lentitud e inefectividad a posteriori de las resoluciones ${ }^{25}$. Precisamente, al tiempo que esos espacios de contención para migrantes se ubican en lugares remotos (como islas o espacios extraterritoriales) o de difícil acceso público (como instalaciones militares o zonas portuarias o aeroportuarias), también están internamente administrados bajo a una sustanciosa incertidumbre jurídica, lo que dificulta la posibilidad de evitar la suspensión de facto de derechos y garantías ${ }^{26}$.

22 T. GAMMELTOFT-HANSEN, N. NYBERG-SORENSEN, (eds.), The Migration Industry and the Commercialization of International Migration, London, Routledge; A. LÓPEZ SALA y D. GODENAU, "Delegando el control migratorio. Una aproximación a las prácticas del outsourcing en España", en A. LÓPEZ SALA, D. GODENAU, Estados de contención, Estados de detención. El control de la inmigración irregular en España, Barcelona, Anthropos. 2017; C. RODIER, El negocio de la xenofobia, Madrid, Clave Intelectual, 2012.

23 C. LEVY, "Refugees, Europe, camps/state of exception: "into the zone", the European Union and extraterritorial processing of migrants, refugees, and asylum-seekers (theories and practice)", Refugee Survey Quarterly, núm 29 vol. 1, 2010, pp.92-119.

24 S. CARRERA y M. STEFAN (eds), Fundamental Rights Challenges in Border Controls and Expulsion of Irregular Immigrants in the European Union Complaint Mechanisms and Access to Justice. Londres: Routledge, 2020.

25 G. CORNELISSE, Immigration detention and human rights: rethinking territorial sovereignty. Brill, 2010.

26 A. LENDARO, "A 'European migrant crisis'? Some thoughts on Mediterranean borders". Studies in Ethnicity and Nationalism, núm 16 vol. 1, 2016, pp. 148-157.

ISSN: 1133-0937

DOI: https://doi.org/10.20318/dyl.2021.6108
DERECHOS Y LIBERTADES

Número 45, Época II, junio 2021, pp. 267-302 
Esta estrategia europea de crear hotspots o centros para la recepción de migrantes rescatados en el Mediterráneo, nos invita a investigar la situación en nuestro contexto donde la especificidad reside en que no hay una declaración formal de la Comisión de creación de hotspots, pero que, en la práctica, tanto por el patrón por el que se rigen estos Centros de Atención Temporal a Extranjeros, como por la presencia de agentes de fronteras europeos vigilantes del cumplimiento de la aproximación europea de puntos críticos, debemos considerarlos como tales.

\section{EL NUEVO MODELO ESPAÑOL DE GESTIÓN GERENCIAL DE LAS LLEGADAS MARÍTIMAS}

El modelo español de control de fronteras marítimas ha consistido en lo que López-Sala ha denominado "reacción dinámica" 27 en tanto que se asemeja a un sistema en el que las estrategias de entrada y las rutas, principalmente en los enclaves de Ceuta y Melilla, el Estrecho y el Archipiélago canario, van modificándose según las medidas de control fronterizo que se implementan. Por ejemplo, en el momento de escritura de este artículo, se ha reactivado de forma importante la ruta hacia las Islas Canarias así como la ruta desde Argelia ${ }^{28}$. Así, concluye López-Sala que el incremento del control sobre alguno de estos puntos ha originado la aparición de nuevas rutas y estrategias. La consolidación del Estrecho como paso de embarcaciones convirtió la vigilancia marítima en una prioridad, llevando a la implementación progresiva del Sistema Integrado de Vigilancia Exterior (SIVE), lo que a su vez derivó, según López-Sala, en la activación de rutas hacia el Mar de Alborán, a los saltos de las vallas fronterizas de Ceuta y Melilla, y hacia las Islas Canarias.

Las relaciones internacionales entre España y Marruecos principalmente, aunque también Mauritania y Senegal son otro elemento a tener en cuenta. La vigilancia fronteriza se trasladó a estos países, origen de las embarcaciones, mediante una significativa aportación de fondos y medios materiales y humanos, así como acuerdos bilaterales de readmisión, consolidando lo

27 A. LÓPEZ SALA, "Política migratoria e inmigración irregular a través de embarcaciones: el caso del archipiélago canario", Anuario CIDOB de la inmigración, núm 0, 2007, pp. 226-244.

28 ElPaís.es "Crecen las llegadas de migrantes desde Argelia tras el freno en Marruecos", 6 de noviembre de 2019; o ElPaís.es "La ruta migratoria desde Argelia enciende las alertas de las autoridades españolas y europeas", 23 de mayo de 2020. 
que se ha denominado "externalización de fronteras" 29 . En la actualidad, el socio principal (e imprescindible) de España en el control de la ruta migratoria del Mediterráneo occidental es Marruecos, que así lo hace valer cada vez que hay que renegociar los acuerdos de pesca de la UE o se pone sobre la mesa la cuestión del Sahara occidental. En octubre de 2018, España donó a Marruecos, y también a Senegal y Mauritania, 108 vehículos y material informático por valor de 3,2 millones de euros. Entre 2019 y 2020 Marruecos viene recibiendo de España 30 millones de euros a cargo de los presupuestos generales del Estado (Consejo Ministros de 19 de julio de 2019), que se incluyen dentro de los 147,7 millones de euros con cargo al Fondo Europeo de Emergencia Fiduciaria para África, así como 389 millones procedentes de los nuevos programas de cooperación de la Comisión Europea (20 diciembre de 2019), para mejorar y actualizar la flota de vehículos con la que reforzar el control de sus fronteras y reprimir así los flujos migratorios irregulares hacia Europa.

Así mismo, la reciente creación de la Autoridad de coordinación de las actuaciones para hacer frente a la inmigración irregular en la zona del Estrecho y el Centro de Coordinación (Acuerdo de Consejo de Ministros de 3 de agosto de 2018), también conocido como ACIE o "Mando Único Operativo", debe interpretarse también en el contexto del nuevo modelo de gestión de las llegadas marítimas. Esta autoridad, ubicada dentro del cuerpo policial-militar de la Guardia Civil, y geográficamente en Málaga, según el acuerdo ministerial, toma decisiones y coordina los principales departamentos y organismos afectados en lo relativo a llegadas marítimas: Fuerzas Armadas, Frontex, Centro Nacional de Inteligencia, Guardia Civil, Policía Nacional, Dirección Adjunta de Vigilancia Aduanera, Capitanías Marítimas, SASEMAR, Secretaría de Estado de Migraciones del Ministerio de Trabajo, Migraciones y Seguridad Social y de las Delegaciones del Gobierno en Andalucía, en Ceuta y Melilla, y Cruz Roja. Una de las principales encomiendas realizadas a este órgano es la coordinación de los recursos humanos y materiales destinados a la gestión y control de la inmigración irregular, entre los que destacan los procedimientos de coordinación de SASEMAR, Policía Nacional y Cruz Roja en el rescate marítimo y traslado a puerto de embarcaciones.

29 R. ZAPATA-BARRERO y J. ZARAGOZA. “Externalización de las políticas de inmigración en España: ¿giro de orientación política en la gestión de fronteras y flujos migratorios? Panorama Social, núm 8, 2008, pp. 186-195. 
Resulta interesante la presencia de la agencia europea Frontex en el Centro de Coordinación (y la ausencia de otras agencias como EASO, Europol, Eu-LISA o Eurojust, presentes en los Hotspots italianos y griegos). Desde la creación en 2006 de la agencia europea para las fronteras exteriores siempre ha puesto el foco en la denominada ruta del Mediterráneo Occidental $^{30}$. A través de las operaciones conjuntas Hera (Islas Canarias y África occidental), Minerva (Estrecho de Gibraltar: Algeciras, Tarifa y Ceuta) e Indalo (Mar de Alborán: Cádiz, Málaga, Granada, Almería y Murcia), Frontex (así otros Estados Miembros) han prestado apoyo (en torno a 180 agentes) a los cuerpos policiales en el control fronterizo, identificación y registro de migrantes irregulares, así como tráfico de personas, drogas, y otras redes criminales con destino la Unión Europea. Durante el 2019, en el contexto de la Operación Conjunta Indalo, se han incorporado lanchas guardacostas, un buque de la Armada Nacional francesa y un avión Beechcraft de la dirección regional guardacostas de aduanas de Marsella, llegando incluso a realizar operaciones de interceptación y rescate en altamar, pero transfiriendo a las personas a las embarcaciones SASEMAR para su traslado a puerto. Desde el 4 de noviembre de 2020, Frontex está presente en las Islas Canarias desarrollando la misión denominada "Canary Islands Focal Point".

En este contexto actual de gestión de las fronteras exteriores, según los datos publicados por $\mathrm{ACNUR}^{31}$ en el portal sobre la situación en el mediterráneo relativo a España, datos proporcionados a su vez por el Ministerio de Interior, del total de entradas por vía marítima (65.383) a fecha de 31 de diciembre de 2018, en base a los principales orígenes, 13.076 serían de nacionalidad marroquí, 13.053 de Guinea Conakry, 10.340 malienses, 5.801 argelinas, 5.273 de Costa de Marfil, 4.080 de Gambia, 2.133 de Senegal y 1.573 de Siria. Si bien luego veremos que la ayuda ofrecida a Marruecos ha tenido la consecuencia directa de la reducción a la mitad de las llegadas, así como la reactivación de la ruta atlántica a Canarias (23029 en 2020), ahora debemos preguntarnos ¿cómo se han gestionado esas llegadas en los últimos años?, precisamente para argumentar que ha habido un cambio en consonancia con el hotspot approach.

30 A. Ruiz Benedicto "El papel de Frontex en la militarización y securitización de los flujos migratorios en la Unión Europea. Barcelona" Centre Delàs d'Estudis per la Pau, 2019.

31 Disponible en $h$ ttps://data2.unhcr.org/en/documents/download/67552 
En estos últimos años, siguiendo en cierto modo la estela de los estudios de criminología crítica ${ }^{32}$ y crinmigración ${ }^{33}$, autores como Fernández-Bessa y Brandariz $^{34}$, y siguiendo esa línea de investigación también Barbero ${ }^{35}$, han observado un "giro gerencial" de la maquinaria de deportación (detención, internamiento y expulsión) de extranjeros, en gran medida motivado por la reducción de recursos y efectivos en momentos de crisis económica, y la necesidad de alcanzar cotas de mayor eficacia policial. Dicho con otras palabras, lograr objetivos con menos recursos/esfuerzos. En otro lugar, Brandariz explica cómo esta evolución gerencial "se pone claramente de evidencia cuando se indaga un conjunto de cambios operativos (de prioridades), institucionales (de organización de las instancias de control), logísticos (de planificación de las necesidades materiales de sistema) e infra-normativos (de niveles inferiores a la Ley y el Reglamento de Extranjería) que han transformado profundamente la realidad del sistema de control migratorio en España" ${ }^{36}$. Para este autor, ahora ya no se sanciona de manera generalizada "a quien se puede", sino cada vez más "a quien se quiere", refiriéndose a determinadas nacionalidades en relación con determinados hechos, y todo ello condicionado por necesidades de legitimidad pública $\mathrm{y}$, sobre todo, de funcionamiento ágil y eficiente -no necesariamente eficaz- de este dispositivo de control. Es dentro de esta lógica gerencial donde me gustaría también ubicar las novedades ocurridas en el contexto de emergencia humanitaria ante las llegadas marítimas y su gestión mediante la creación de los CATE, en detrimento de los CIE.

En primer lugar, es preciso puntualizar que para materializar el internamiento de un extranjero en un CIE se requieren una serie de condicionantes,

32 D. MELOSSI, M. SOZZO; J.A. BRANDARIZ (ed.), The political economy of punishment today: visions, debates and challenges, Routledge, 2017.

33 J. STUMPF, "The Crimmigration Crisis: Immigrants, Crime, and Sovereign Power". American University Law Review, vol. 56, p. 367, 2006; M. VAN DER WOUDE; V. BARKER; J. VAN DER LEUN. Crimmigration in Europe. European Journal of Criminology, vol 14, núm. 1, 2017.

34 C. FERNÁNDEZ BESSA, y J. A. BRANDARIZ GARCÍA, "Transformaciones de la penalidad migratoria en el contexto de la crisis económica: El giro gerencial del dispositivo de deportación", en InDret, núm 4, 2016, pp. 1-25.

35 BARBERO, Iker. Estudio jurídico-empírico de la detención, internamiento y expulsión de extranjeros en el País Vasco: especial examen a las expulsiones exprés. Migraciones. Publicación del Instituto Universitario de Estudios sobre Migraciones, [S.1.], 2018, núm. 45, p. 143-171

36 Entrevista a José Ángel Brandariz: "No hay un modelo de control migratorio propiamente europeo, sino diversas combinaciones en diversos Estados" Disponible en $h$ ttps://blogs. publico.es/red-juridica/2019/07/12/no-modelo-control-migratorio-europeo/

ISSN: 1133-0937

DOI: https://doi.org/10.20318/dyl.2021.6108
DERECHOS Y LIBERTADES

Número 45, Época II, junio 2021, pp. 267-302 
requerimientos, y en cierta medida, garantías jurídicas ${ }^{37}$. Antes de nada, es necesario que el órgano policial que pretende el internamiento solicité a la dirección del CIE la existencia de plazas disponibles. Después, el internamiento debe ser autorizado mediante auto judicial emitido por el juez o jueza de instrucción del lugar de la detención, previa vista donde interviene la fiscalía y la defensa letrada del extranjero. En caso de autorización del internamiento, cabe recurso de reforma y posterior apelación, dilatando varios días los plazos que materialicen el internamiento. Ante estas condiciones legales, es evidente la ineficacia de los CIE como mecanismos de gestión de urgencia ante las llegadas a costas de personas a quienes la policía quiere identificar a fin de incoar un procedimiento de devolución (58 LOEx $)^{38} \mathrm{y}$, no podemos olvidar, para cumplir requerimiento de incluir los datos en EURODAC, en el contexto de la nueva estrategia comunitaria de migración y asilo ${ }^{39}$.

En segundo lugar, atendiendo a una serie de datos sobre internamientos en CIE (Tablas 1 y 2), queremos argumentar que, por un lado, si bien hay una tendencia de descenso pronunciado de los internamientos, en los últimos años las cifras se han mantenido por el uso de los CIE para la contención de recién llegados; y por otro lado, hay que señalar el carácter diferenciado de los distintos CIE en funcionamiento, en relación a la función que cumplen, siendo algunos centros de recepción y otros centros de expulsión (siempre siendo conscientes de que determinados momentos, ante el desbordamiento de CIE como Algeciras o Murcia, personas recién llegadas son trasladadas a CIE como Madrid, Valencia o Barcelona) las tasas de capacidad de expulsión de cada uno de los CIE.

37 M. MARTINEZ ESCAMILLA, "Para que el derecho no se detenga a las puertas de los CIE: análisis del régimen jurídico del internamiento de extranjeros". Anuario de derecho penal y ciencias penales, 2009, núm. 62, vol. 1, p. 253-281. FERNADEZ-BESSA, Cristina Los centros de Internamiento de Extranjeros (CIE). Una introducción desde las Ciencias Penales, Iustel, Madrid.

38 Ante la entrada irregular cuando ésta se produce por puesto no habilitado, la Ley de Extranjería, en su artículo 58.3b), prevé el procedimiento de “devolución” consistente en el retorno forzoso del extranjero a su país de origen, habilitando el internamiento en CIE como medida cautelar cuando se prevea que no se podrá ejecutar la devolución en el plazo de 72 horas (58.6 LOEX).

39 COMISIÓN EUROPEA, Hacia un sistema europeo común de asilo, equitativo y sostenible, 4 de mayo de 2016, Disponible en https://ec.europa.eu/commission/presscorner/detail/es/IP_16_1620 
Tabla 1: Evolución internamiento CIE (2009-2018)

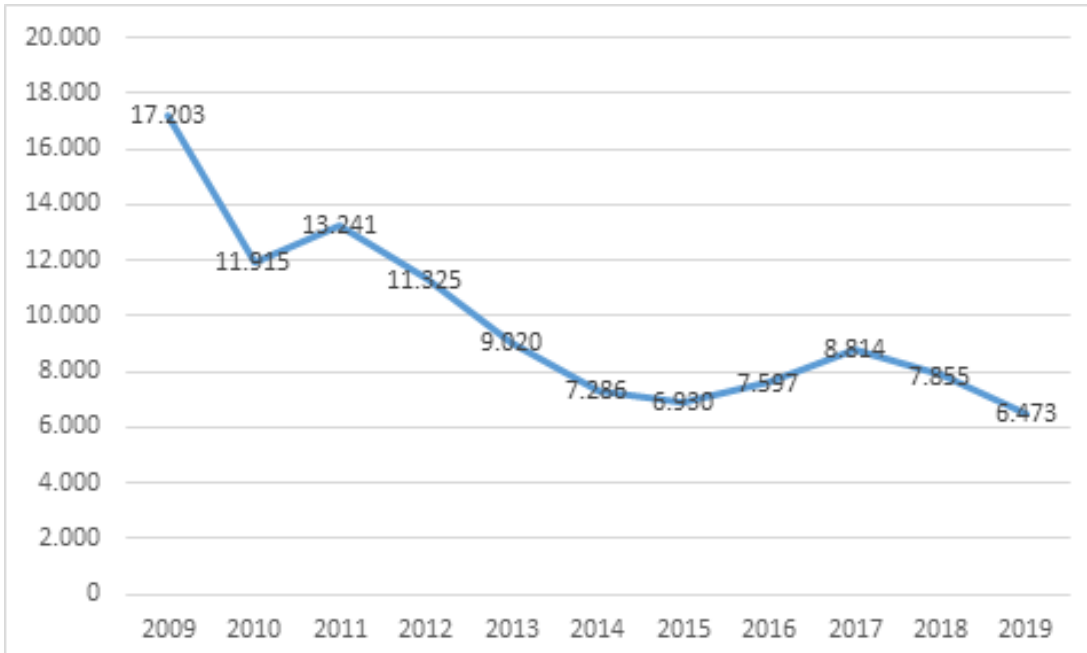

Fuente: Elaboración propia a partir de Ministerio del Interior e Informes anuales del Mecanismo Nacional de Prevención de la Tortura (Defensor del Pueblo).

Si tomamos como referencia el año 2016 (no hay datos más actuales de tasa de expulsabilidad), CIE como Las Palmas (0.6), Tenerife (12.09) y sobre todo Algeciras (14.99), presentan unas tasas de capacidad de expulsión proporcionalmente relativamente bajas, ya que históricamente han cumplido la función de centro de primera acogida; por el contrario, Madrid (46.16), Valencia (59.10) o Murcia (57.95) reportaban unas tasas de materialización de la expulsión relativamente altas, (si bien también reciben personas recién llegadas, bien a aeropuertos como Barajas o El Prat, como a costas) en tanto que su principal función ha sido la de recibir personas procedentes de distintas partes del territorio para materializar la expulsión.

Tabla 2: Tasa de capacidad de expulsión por cada CIE (2016)

\begin{tabular}{|c|c|c|c|c|c|c|c|}
\hline 兒 & 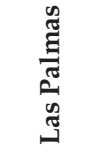 & 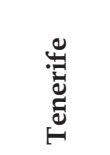 & 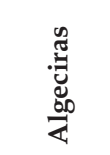 &  & 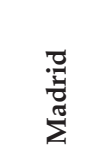 & 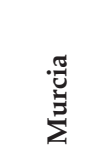 & 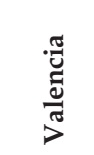 \\
\hline Expulsabilidad & $0.63 \%$ & $12.09 \%$ & $14.99 \%$ & $21.43 \%$ & $46.13 \%$ & $57.95 \%$ & $59.10 \%$ \\
\hline
\end{tabular}

* Barcelona permaneció cerrado por reformas durante varios meses en este periodo

ISSN: 1133-0937

DOI: https://doi.org/10.20318/dyl.2021.6108
DERECHOS Y LIBERTADES

Número 45, Época II, junio 2021, pp. 267-302 
Fuente: Informe anual del Mecanismo Nacional de Prevención de la Tortura (Defensor del Pueblo).

De nuevo, si miramos los motivos del internamiento en el 2018, año de mayor afluencia de llegas a costas (Tabla 3), observamos que mientras que determinados CIE acogen proporcionalmente más personas por cuestiones de seguridad y expulsiones previstas en el código penal, o por situación administrativa irregular, como puede ser Barcelona, Valencia o Madrid; en otros CIE, es mucho mayor (en torno al 85-90\%) el peso de las personas internadas por entrada irregular. Recordemos de nuevo que es habitual reubicar recién desembarcados también en CIE alejados de las costas, de hecho 817 de las 820 personas internadas en Barcelona lo habían hecho en patera o buque, 994 de 1061 en Madrid, 657 de 665 en Valencia. 


\begin{tabular}{|c|c|c|c|c|}
\hline$\therefore$ & స్ & $\begin{array}{l}\infty \\
\stackrel{\infty}{\sigma}\end{array}$ & $\stackrel{\circ}{\stackrel{\circ}{N}}$ & $\stackrel{ }{~}$ \\
\hline 胥 & 㐌 & $\begin{array}{l}\stackrel{\circ}{\circ} \\
\stackrel{n}{n}\end{array}$ & $\begin{array}{l}\stackrel{L}{a} \\
\stackrel{\infty}{n}\end{array}$ & 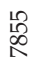 \\
\hline$\therefore$ & $\begin{array}{l}0 \\
n^{\circ}\end{array}$ & $\begin{array}{l}\text { ป } \\
\text { d }\end{array}$ & $\stackrel{\infty}{\rightarrow}$ & $\underset{ }{\stackrel{ }{2}}$ \\
\hline 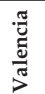 & กิ & ठे & 늉 & ूू \\
\hline$\therefore$ & $\stackrel{+}{\text { ch }}$ & 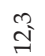 & $\stackrel{\text { I }}{\stackrel{\infty}{\infty}}$ & \& \\
\hline 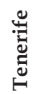 & $\stackrel{\stackrel{2}{N}}{ }$ & \& & $\stackrel{10}{\sigma}$ & $\stackrel{尺}{\circledR}$ \\
\hline$\therefore$ & $\stackrel{\infty}{\rightarrow}$ & $\begin{array}{l}\text { ñ } \\
\stackrel{n^{2}}{ }\end{array}$ & $\begin{array}{c}\text { बे } \\
\text { - }\end{array}$ & \& \\
\hline 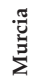 & $\ddot{\sim}$ & క్సి &  & $\overrightarrow{\widetilde{g}}$ \\
\hline$\therefore$ & ते & $\begin{array}{l}\text { ले } \\
\text { ले }\end{array}$ & 点 & \& \\
\hline 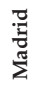 & ํำ & đ্ণ & 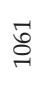 & ఫొ \\
\hline$\stackrel{\circ}{\circ}$ & $\mathscr{L}^{2}$ & $\begin{array}{l}\infty \\
\infty\end{array}$ & $\underset{+}{\stackrel{\infty}{+}}$ & 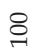 \\
\hline 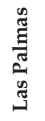 & $\stackrel{\infty}{\sim}$ & $\stackrel{\Delta}{N}$ & 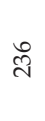 & $\stackrel{\infty}{\stackrel{\Delta}{*}}$ \\
\hline$\therefore$ & $\stackrel{\infty}{\wedge}$ & ते & $\vec{\sigma}$ & $\underset{\sim}{\stackrel{-}{2}}$ \\
\hline  & 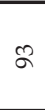 & $\stackrel{\overbrace{}}{\stackrel{N}{N}}$ & 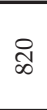 & $\begin{array}{l}\infty \\
\underset{\sim}{二}\end{array}$ \\
\hline$\therefore$ & $\stackrel{+}{\rightarrow}$ & $\stackrel{0}{\wedge}$ & $\sigma$ & \& \\
\hline 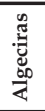 & $\vec{\sim}$ & $\exists$ & $\begin{array}{l}\vec{D} \\
\vec{n}\end{array}$ & fo \\
\hline 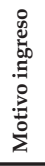 & 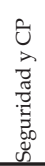 &  & 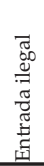 & 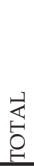 \\
\hline
\end{tabular}

ISSN: 1133-0937

DOI: https://doi.org/10.20318/dyl.2021.6108
DERECHOS Y LIBERTADES

Número 45, Época II, junio 2021, pp. 267-302 
En tercer lugar, en la línea de lo que decía Brandariz de que hay una selección de orígenes nacionales, según el informe 2018 del Servicio Jesuita al Migrante (SJM), en los momentos de mayores llegadas de 2018 principalmente, desde autoridades gubernamentales se decidió dejar de internar a subsaharianos, dando prioridad al internamiento de marroquíes (2.801) y argelinos (2.511) por la facilidad con que pueden ser devueltos ${ }^{40}$. Gracias a esta política, se ha producido una subida de la eficacia de los CIE como centros de expulsión. Y, al mismo tiempo, siguiendo la lógica de la eficiencia y reducción de costes económicos y burocráticos, apenas un $16.8 \%$ de los 13.316 marroquíes llegados en 2018 pasó por un CIE, ya que en su mayoría son retenidos en calabozos policiales y devueltos directamente en las 72 horas posteriores a su llegada. También es cierto que, según informantes cualificados, en los últimos meses de 2019, ante las llegadas se marroquíes procedentes de la zona del Rif, en la mayoría de los casos, se estaba autorizando su detención en los CATE y decretando su puesta en libertad puesto que muchos o no eran admitidos por Marruecos o porque solicitaban protección internacional por persecución política.

En definitiva, el uso de los CIE como dispositivo de contención han evolucionado en los últimos años siguiendo una lógica gerencial evidente: se interna menos en 2018 que en 2009; cuando se interna, se interna dando preferencia a las nacionalidades con mayor probabilidad de materialización de la expulsión; y si es posible, se procurará ejecutar la expulsión sin internamiento (ya sea por la programación de vuelos o por la cercanía y admisión del país). De las 65.383 personas que habrían entrado de forma irregular en 2018 (32.492 en $2019^{41}$ y 42.861 en 2020), si se dice que solo una parte de los nacionales de Marruecos y Argelia (en torno a 26.000) son internados en CIE, ¿Qué sucedió con el resto, principalmente originarios de Guinea Conakry (12.780), Mali (11.903)? A fecha de 31 de diciembre de 2019, ACNUR ${ }^{42}$ contabilizaba 8.271 marroquíes, 5.025 argelinos, 5.124 guineanos, 3.298 malienses, 2.867 costamarfilenses, 2.378 senegaleses, 1.238 tunecinos o 1.031 sirios, entre otros ¿Cómo se están gestionando estas llegadas? Su destino principal (juntos con los CETIs) son los Centros de Atención Temporal de Extranjeros o CATE, centros de detención con tintes humanitarios.

40 SERVICIO JESUITA AL MIGRANTE, Informe CIE 2018: Discriminación de Origen Disponible en https://sjme.org/publicacion/informe-cie-2018-discriminacion-de-origen/

41 Disponible en https://data2.unhcr.org/en/documents/download/73187

42 Disponible en https://data2.unhcr.org/es/documents/details/73591 


\section{LOS CENTROS DE ATENCIÓN TEMPORAL DE EXTRANJEROS}

De entrevistas mantenidas con informantes cualificados, podemos establecer el siguiente modus operandi para la detención en CATE. Una vez es localizada la patera en altamar, ya sea a través del SIVE o mediante un llamamiento de socorro desde la propia patera, es el Mando Único Operativo quién, tras consultar con Marruecos y comprobar la ubicación de la embarcación en la zona SAR (Search and Rescue), decide cuál es el puerto de destino. A la llegada de la embarcación de salvamento marítimo a puerto, quien técnicamente procede a la detención es la Guardia Civil por razón de competencia en control de puertos y seguridad en fronteras. Además, también aguardan la policía portuaria, Frontex, Policía Nacional y la Cruz roja. Los primeros en subir a la embarcación son Frontex y Policía Nacional para obtener información de primera mano sobre las cartas de navegación, las circunstancias y coordenadas del rescate y tipo de patera/motor. Posteriormente, Cruz Roja entra para hacer una primera evaluación por si hay personas que necesitan evacuación urgente. Así, los primeros en salir son enfermos, mujeres y menores, que en ocasiones son trasladados o hospitales o albergues de distintas ONG, aunque, como han denunciado organizaciones sociales y así ha constatado el Defensor del Pueblo, habitualmente mujeres y menores permanecen encerrados en los CATE incluso en celdas colectivas sin diferenciar con los hombres. Posteriormente van desembarcando los hombres en grupos de 10 personas aproximadamente, para ir realizando un primer triaje que en ocasiones se les pone pulseras de colores dependiendo de su estado de salud. Durante el proceso de reseña policial (toma de huellas fotografías y otros datos biométricos), agentes de Frontex pueden ir seleccionando algunos de los migrantes para un interrogatorio más a fondo. Finalmente, a lo largo de los días de detención, van recibiendo la visita de abogados y abogadas de los turnos de extranjería específicos para las llegadas a costas, para prestar asistencia bien en la tramitación de la orden de devolución o en la solicitud de protección internacional. Respecto a esto último, también suele estar presente un equipo de CEAR (organización que ganó el concurso licitado directamente por ACNUR) ${ }^{43}$ para informar de forma colectiva sobre protección internacional y, en algunos lugares, Save the Children por si hubiera niños y niñas menores no acompañadas. Actualmente, las so-

43 CEAR, "CEAR y ACNUR se unen para facilitar la identificación de refugiados en costas”, 14 de agosto de 2018, Disponible en https://www.cear.es/cear-acnur-identificacion-refugiados-costas/

ISSN: 1133-0937

DOI: https://doi.org/10.20318/dyl.2021.6108
DERECHOS Y LIBERTADES

Número 45, Época II, junio 2021, pp. 267-302 
licitudes de protección internacional que se formalizan en los CATE siguen el procedimiento previsto para la solicitud en territorio, y no el previsto para fronteras y CIE, con unos plazos mucho más ajustados. Una vez realizadas todas las actuaciones policiales e identificación de la persona, la policía puede optar por el traslado a Centro de Internamiento, la devolución inmediata a través de la frontera con Marruecos, o la puesta en libertad con una orden de devolución incoada o una cita para el planteamiento formal de la solicitud de asilo. Respecto a este último aspecto es necesario señalar que si bien en los momentos más álgidos del 2017 y 2018, había una fuerte descoordinación dando lugar a que muchas personas una vez liberadas quedaban sin ningún tipo de asistencia, o eran trasladadas a otros lugares del estado de forma caótica ${ }^{44}$. En la actualidad, se han ido articulando una serie de centros denominados Centros de Atención de Emergencia y Derivación (CAED) ${ }^{45}$, gestionados principalmente por la Cruz Roja y CEAR a través de una concesión del Ministerio de Migraciones, Trabajo y Seguridad Social ${ }^{46}$; así como redes alternativas (Red \#AcogidaDigna, redes informales...) establecidas por todo el Estado para dar una acogida digna quienes no acceden a los recursos públicos.

\subsection{Surgimiento y situación actual}

Como decíamos en la introducción, ya desde al año 2017 se vienen utilizando unos rudimentarios dispositivos para la contención de personas extranjeras llegadas por vía marítima llamados inicialmente Centros de Primera Asistencia y Detención (tiendas de campaña levantadas por la Unidad Militar de Emergencias), ubicados en Cartagena, Almería, Motril, Málaga, Algeciras y Tarifa (Defensor del Pueblo 2017 y 2018), y que en la actualidad han pasado a denominarse los Centros de Atención Temporal de Extranjeros o CATE de San Roque (Cádiz), Málaga, Motril (Granada), Almería, y más recientemente los ubicados en Canarias (Arguineguín,

44 Naiz.info, "Abandonan a 46 refugiados en la estación de autobuses de Donostia", 18 de junio de 2018.

45 ElDirariodeAlmeria.es "Un nuevo centro para atender a los inmigrantes llegados en pateras", 26 de julio de 2019; CadenaSer.com "El Gobierno inaugura un CAED en Málaga que permitirá acoger a 230 personas", 27 de Agosto de 2019.

46 Real Decreto 301/2019, de 26 de abril, por el que se regula la concesión directa de una subvención a Cruz Roja Española para la realización del programa de atención a inmigrantes llegados a las costas españolas o a las ciudades de Ceuta y Melilla a través de las fronteras terrestres en el año 2019. 
Barranco Seco en Gran Canarias, El Hierro, Muelle de Puerto del Rosario de Fuerteventura y Adeje en Tenerife ${ }^{47}$ )

Haciendo un breve recorrido por cada uno de los centros, más allá de elementos específicos, vemos una arquitectura común: la incertidumbre real y jurídica generada por la permanente provisionalidad. Tras la una primera fase de tiendas de campaña, el actual CATE de Cádiz, ubicado Puerto de Algeciras, (aunque técnicamente pertenece al municipio de San Roque, de ahí sus múltiples denominaciones) concretamente en el antiguo Centro de formación portuaria e industrial de Crinavis, permanece abierto oficialmente desde el 2 de agosto de 2018. En Málaga, durante 2017 y 2018, se emplearon instalaciones como las casetas del Recinto Ferial o Pabellón Polideportivo Municipal José Paterna. En la actualidad, el nuevo CATE (inaugurado en 29 agosto de 2019) es un espacio cedido por el propio Puerto de Málaga a la Delegación del Gobierno Central, de unos $2.500 \mathrm{~m}^{2}$ en el que hay prevista una ocupación de 300 personas en unos cinco módulos independientes prefabricados, tres de ellos para estancias de migrantes, uno para los servicios asistenciales y dos para agentes policiales (uno Policía Nacional y otro Frontex $)^{48}$. La APDHA siempre ha señalado irregularidades formales en lo que refiere a cuestiones técnicas de la creación y construcción del centro. En las costas granadinas, lo que inicialmente se denominó Centro de Primera Asistencia y Detención de Extranjeros de Motril, consistía en las tiendas de campaña levantadas por la Unidad Militar de Emergencias que servían tanto para labores documentales, asistencia médica, como para alojamientos, aseos y comedores. A esperas de que se abra el nuevo centro, ubicado en una parcela de $2.000 \mathrm{~m} 2$ del mismo puerto y construido a base de módulos prefabricados, similar al de Málaga, el actual CATE de Motril se encuentra ubicado en unas antiguas instalaciones del puerto pesquero. Se trata de un centro sin apenas ventilación con el exterior ni calefacción, y con una distribución interior a base de celdas con puertas de rejas donde se encierran 20 a 30 personas con colchones en el suelo y un solo baño. El CATE de Almería se encuentra ubicado en el denominado Muelle de Poniente y consiste en una serie de módulos prefabricados. En Murcia, si bien no hay declarado un CATE en funcionamiento (aunque sí construido), sí hay constancia de la instalación de un

47 Se tiene constancia de algunos de estos centro por el informe del Defensor del Pueblo sobre "La migración en Canarias" (2021) https://www.defensordelpueblo.es/wp-content/ uploads/2021/03/INFORME_Canarias.pdf

48 APDHA Málaga tiene un CATE. Centro de Detención de Migrantes Disponible en https://www.facebook.com/apdha.malaga/videos/932815713732907/

ISSN: 1133-0937

DOI: https://doi.org/10.20318/dyl.2021.6108
DERECHOS Y LIBERTADES

Número 45, Época II, junio 2021, pp. 267-302 
denominado "Dispositivo de Acogida", consistente en carpas y tiendas de campaña en el Muelle de la Curra, en el Arsenal del Puerto de Cartagena. En las Islas Canarias, ya en informes del Defensor del Pueblo de $2018^{49}$ se hacía mención a un Centro de Primera Asistencia y Detención en Adeje, Santa Cruz de Tenerife. Ante el aumento de llegadas desde octubre de 2019, se comenzaron decretando los internamientos en el CIE de Hoya Fría (Tenerife) o en Barranco Seco (Gran Canaria), o ubicando en instalaciones improvisadas, edificios en desuso cedidos por los ayuntamientos o centros de ONG. El primer gran espacio de detención/confinamiento bajo la denominación de CATE fue el Muelle del puerto de Arguineguín (en el municipio de Mogán, al sur de la Isla de Gran Canaria). Desde 20 de agosto de 2020 desembarcaron más de 20.000 personas, llegando en su punto más álgido de hacinamiento con 2600 personas (incluidos menores, acompañados y no acompañados). Las condiciones eran, en palabras del Defensor del Pueblo, "inhumanas" 50. Las personas permanecían varias semanas durmiendo en el suelo sin techo, con escasos recursos de aseo ( 25 baños químicos y 12 duchas que se fueron instalando muy paulatinamente), y sin un plan definido de distanciamiento social más allá de vallas de obra a modo de pequeños cercados, dando lugar a números contagios por Covid-19. Si bien a finales de noviembre se decretó su cierre y apertura del CATE de Barranco Seco (consistente en una serie de tiendas de campaña militar), se sigue empleando como puerto de desembarco, primera identificación por parte de Policía nacional y Frontex, y triaje sanitario por parte de Cruz Roja.

En lo que refiere a las cifras de detención en estos centros (Tabla 4), debemos señalar los siguientes elementos. En primer lugar, es necesario decir que no se trata de datos publicados de oficio, si no obtenidos bien a partir de mecanismos de control parlamentario o a través de solicitudes propias en el Portal de Transparencia, lo que ya de por sí atribuye elementos de voluntad de opacidad estos centros. Además, es preciso resaltar que la originalidad de estos datos frente a otros ya hechos públicos, reside en que en la pregunta parlamentaria formulada por el diputado EH Bildu, Jon Iñarritu, de 21 de julio de 2019 (184/481, XIII legislatura), solo se mencionaban adultos, dejando fuera a los menores. En segundo lugar, convendría prestar cierta cautela

49 DEFENSOR DEL PUEBLO. Ficha de seguimiento de la visita realizada por el MNP. 2018. Disponible en https://www.defensordelpueblo.es/evento-mnp/centro-de-primeraasistencia-y-detencion-de-extranjeros-en-adeje-santa-cruz-de-tenerifel

50 https://www.defensordelpueblo.es/evento-mnp/centro-de-atencion-temporal-de-extranjerosdel-muelle-del-puerto-de-arguineguin-las-palmas-de-gran-canarial 
a la certeza de los datos, especialmente de las primeras fechas, ya que como venimos diciendo, la improvisación e incertidumbre jurídica de estos mecanismos ha podido dar lugar a la no inclusión en esta tabla de detenciones en dispositivos no considerados inicialmente como CATE (Málaga es un ejemplo de ello dónde se sabe que se empleaban polideportivos y recintos feriales como lugar de detención y, sin embargo, no constan datos previos a la mitad del 2019).

Con todo, vemos que el 2018 es sin duda el momento de mayor rendimiento de estos centros, con al menos 33.619 personas detenidas, de las cuales más de 3.000 eran personas menores de edad. Esto último, es relevante en el sentido de que algunos niños y niñas que migran acompañados, no están detenidos en el CATE por la detención de sus familiares (como sucede en los CIE), si no que ellos mismos son objeto de detención para identificación. Por un lado, y por analogía con los CIE, el artículo 62 bis i) de la LOEx posibilitaría que los extranjeros sean internados "en su compañía a sus hijos menores, siempre que el Ministerio Fiscal informe favorablemente tal medida" ${ }^{51}$. En el caso de los CATE, si bien en algunos centros sí hay módulos separados para familias, en otros persiste el internamiento en módulos comunes y no se ha tenido constancia de que la práctica habitual sea el informe favorable previo de la Fiscalía. Pero, por otro lado, en el caso de menores no acompañados debemos recordar que la LOEx (art.62.4) prohíbe taxativamente el internamiento, debiendo guiarse por los parámetros establecidos en la Ley Orgánica 1/1996, de Protección Jurídica del Menor (LOPJM). Aun así, en diversas ocasiones se ha tenido constancia, incluso evidenciado con una visita de personal de la Oficina del Defensor del Pueblo ${ }^{52}$, del internamiento en CATE de menores no acompañados.

51 El Tribunal Supremo, por sentencia de 10 febrero 2015, declaró inaplicable, el inciso "y existan en el centro módulos que garanticen la unidad e intimidad familiar" del artículo 62 bis 1.i) de la LOEx; así como inválidos y nulos los incisos, "en la medida de lo posible", del artículo 7.3, segundo párrafo, y "y existan en el centro módulos que garanticen la unidad e intimidad familiar" del artículo 16.2.k) del Reglamento de Funcionamiento y Régimen Interior de los Centros de Internamiento de Extranjeros; obligando a facilitar alojamiento separado a las familias internadas, tal como impone apartado 2 del artículo 17 de la Directiva de Retorno.

52 Publico.es, "Interior encerró en "celdas para adultos" a menores llegados en patera a Málaga. Según constató el Defensor del Pueblo en una visita al Centro de Asistencia Temporal de Extranjeros (CATE) de la ciudad el 9 de septiembre de 2019, había niños "tanto acompañados como sin acompañar" en estancias no adecuadas. Ha puesto el caso en manos de la Fiscalía". 23 de noviembre de 2019. 
En general, haciendo un análisis más pormenorizado por centros debemos decir que si bien San Roque-Cádiz es el más grande en cuanto a capacidad, otros CATE mucho más pequeños presentan tasas de retención similares, cómo es el caso de Almería o Motril, denotando un evidente uso excesivo y un potencial hacinamiento en estos últimos. Finalmente, si bien la cifra para el 2019, ha descendido, se trata de una cifra suficientemente alta para poder afirmar la consolidación de estos centros como mecanismo de detención ante la llegada a costas.

Tabla 4 Datos de detención en CATE (2017-10 diciembre de 2019)

\begin{tabular}{|l|c|c|c|c|c|}
\hline & Motril & San Roque & Almería & Málaga & Murcia \\
\hline Capacidad & 90 & 450 & 180 & 300 & ¿? \\
\hline $\mathbf{2 0 1 7}$ & 3.838 & No habilitado & 5.567 & No habilitado & No habilitado \\
\hline $\mathbf{2 0 1 8}$ & $\begin{array}{c}9.497 \\
(572 \text { menores })\end{array}$ & $\begin{array}{c}11.885 \\
(2.025 \text { menores })\end{array}$ & $\begin{array}{c}12.234 \\
(589 \text { menores })\end{array}$ & No habilitado & No habilitado \\
\hline $\mathbf{2 0 1 9}$ & $\begin{array}{c}3.414 \\
(178 \text { menores })\end{array}$ & $\begin{array}{c}5.344 \\
(1.273 \text { menores })\end{array}$ & $\begin{array}{c}5.488 \\
(284 \text { menores })\end{array}$ & $\begin{array}{c}{ }^{*} 1.042 \\
(49 \text { menores })\end{array}$ & No habilitado \\
\hline
\end{tabular}

* $\quad$ Abierto el 29 de agosto de 2019

Fuente: elaboración propia a partir de pregunta parlamentaria (184/481 de 2019) y respuesta de Portal de Transparencia con fecha de 10 de diciembre de $2019^{53}$.

Respecto a los CATE de Canarias, es a partir del informe del Defensor del Pueblo ${ }^{54}$ que se sabe que en el CATE de Barranco Seco ha habido un total de 5.564 personas detenidas en esas instalaciones hasta el 1 de febrero 2021. De estas, 4.806 eran hombres (3464 marroquíes y 1342 subsaharianos), 232 mujeres (125 marroquíes y 107 subsaharianas) y 526 menores (403 marroquíes y 123 subsaharianos). En el mismo informe se detalla que en el CATE de Adeje durante 2020 han estado detenidas 3.200 personas, de ellas $108 \mathrm{mu}$ jeres y 514 menores (10 de ellas niñas, 9 de Costa de Marfil y una de Guinea Conakry).

De la lectura de los últimos informes del Defensor del Pueblo, en calidad de Mecanismo para la Prevención de la Tortura (MNPT), se observa que las deficiencias principales que ha denunciado esta institución han sido las

53 Si bien se ha solicitado actualización de la información vía Portal de Transparencia, a fecha de entrega de este artículo no se ha recibido contestación alguna.

54 DEFENSOR DEL PUEBLO, La migración en Canarias Estudio. Madrid: Defensor del Pueblo, 2021. 
condiciones habitacionales de estos centros donde no hay separación entre hombres y mujeres y menores, el hacinamiento en celdas colectivas sin literas, baños y duchas en el exterior y la ausencia de sistemas de calefacción en invierno ${ }^{55}$. Recordemos que, a pesar de tratarse de las costas mediterránea y atlántica-canaria, las condiciones climatológicas en otoño e invierno pueden llegar a ser verdaderamente adversas. En lo que respecta a elementos relativos a la situación de detención, el MNPT ha señalado en diversas ocasiones la ausencia de libros de registro y custodia de detenidos (obligatorios en comisarías), personal policial con funciones encomendadas de seguridad y no formadas técnicamente en trabajos con personas en situaciones de especial vulnerabilidad ${ }^{56}$, lecturas de derechos y asistencias letradas colectivas y en condiciones inadecuadas para garantizar las privacidad entre detenido y letrado, escasa información sobre protección internacional, así como infraestructuras y medios técnicos como fotocopiadoras para cumplimentar formularios sin necesidad de desplazamientos a comisarías para obtener copias ${ }^{57}$. Un elemento interesante que señala el MNPT es la diversidad por demarcaciones policiales de las resoluciones donde se constata la ausencia de algunas órdenes de devolución sin que consten las coordenadas del lugar exacto de la interceptación de la embarcación para constatar si se trataba de un acceso irregular a territorio o de un rescate en aguas internacionales ${ }^{58}$.

Por todo ello, reiteramos la situación sociológica de incertidumbre y provisionalidad estructural y arquitectónica que se traslada a las condiciones deplorables en la que se encuentran en la mayoría de ocasiones las personas detenidas en los CATE. Esta incertidumbre tiene su origen, sin duda, en la ausencia de una regulación positiva que se ajuste a Derecho y ofrezca elementos tanto a la Administración para realizar su labor conociendo los límites de su actuación, como a las organizaciones sociales que buscan denunciar esas actuaciones que superarían los límites legales.

\subsection{Naturaleza jurídica}

El primer rasgo que debemos analizar en lo que refiere a la naturaleza jurídica y, en consecuencia, al régimen de gobierno de estos centros de de-

55
$56 F E N S O R$ DEL PUEBLO. Informe Anual 2017. Mecanismo Nacional de Prevención, p 77 y ss.
56 DEFENSOR DEL PUEBLO. Informe Anual 2017. Mecanismo Nacional de Prevención, p 92 y ss.
57 DEFENSOR DEL PUEBLO. Informe Anual 2018. Mecanismo Nacional de Prevención.
58 DEFENSOR DEL PUEBLO. Informe Anual 2018. Mecanismo Nacional de Prevención, p 84 
tención, es la situación de alta ambigüedad jurídica desde el momento que, a diferencia de los CIE, no están mencionados en la LOEx, y mucho menos desarrollados ni en el reglamento de la $\operatorname{LOEx}^{59}$ ni en el de los CIE (RCIE) ${ }^{60}$. En tanto que son centros de detención, los CATE tampoco encuentran encaje dentro de lo previsto en el artículo 264 y siguientes del reglamento de la LOEx que se refiere a los denominados "Centros de migraciones", insertos dentro de una red pública con fines de integración social y dependientes del Ministerio de Inclusión, Seguridad Social y Migraciones (donde sí podrían enmarcarse los Centros de Estancia Temporal de Inmigrantes o CETI de Ceuta y Melilla). Por tanto, su definición normativa, lejos de buscarse en un texto normativo, debe buscarse por un lado, en la ya mencionada respuesta del Gobierno del Estado en sede parlamentaria (184/481), de 21 de julio de 2019, en la que se declara que "los CATE tienen dependencia orgánica de la plantilla policial donde se hallan localizados, por lo que la naturaleza jurídica de dichos centros es la misma que la dependencia policial a la que se encuentran adscritos"; y por otro lado, en la Resolución de 23 de julio de 2018, de la Secretaría de Estado de Seguridad ${ }^{61}$, que los define como "instalaciones concebidas para realizar las primeras actuaciones en un tiempo máximo de estancia de 72 horas mientras se tramitan las diligencias iniciales de identificación y comprobación de antecedentes para después ser derivados a CIE o a disposición de las ONG".

Buscando la justificación normativa que todo órgano administrativo debe tener para su creación, debemos ir al "Acuerdo del Consejo de Ministros de 1 de febrero de 2019, por el que se adoptan medidas adicionales para reforzar las capacidades operativas y garantizar la adaptación permanente de la Autoridad de Coordinación de las actuaciones para hacer frente a la inmigración irregular en la zona del Estrecho de Gibraltar, mar de Alborán y aguas adyacentes, para el cumplimiento de las funciones que le fueron

59 Real Decreto 557/2011, de 20 de abril, por el que se aprueba el Reglamento de la Ley Orgánica 4/2000, sobre derechos y libertades de los extranjeros en España y su integración social, tras su reforma por Ley Orgánica 2/2009.

60 Real Decreto 162/2014, de 14 de marzo, por el que se aprueba el reglamento de funcionamiento y régimen interior de los centros de internamiento de extranjeros.

61 Resolución de 23 de julio de 2018, de la Secretaría de Estado de Seguridad, por la que se declara de emergencia la tramitación de diversos expedientes de contratación para atender las necesidades de alojamiento manutención limpiezas y otras producidas ante la llegada inesperada y masiva de embarcaciones con inmigrantes a las costas españolas especialmente el arco sur Almería Granada Málaga Cádiz y Huelva. 
encomendadas por el Acuerdo del Consejo de Ministros de 3 de agosto de 2018", cuando dice que es el Mando Único quien determina "los puertos de desembarco de los inmigrantes irregulares y posibilita una asistencia integral a través de los Centros de Atención Temporal de Extranjeros (CATE). (...) Para ello, se ha procedido al acondicionamiento de los CATE del puerto de la Bahía de Algeciras (San Roque) y se está tramitando la adaptación de los existentes en los puertos de Motril, Málaga y Almería". Por lo tanto, de la lectura de este texto se desprende que se enmarcan dentro del mecanismo de coordinación del Mando Único, sin embargo, un acuerdo de Consejo de Ministros no es base jurídica suficiente para la creación de centros de detención. Recordemos que al comienzo de este artículo decíamos que para la creación de los CIE es necesaria una orden ministerial, es decir, un reglamento. En definitiva, es importante señalar la vulneración del principio de legalidad en lo que refiere a la propia existencia de tales centros. La ausencia de normas de rango previsto en el ordenamiento para su creación, entre otras cuestiones conflictivas, dificulta el control de legalidad ante la jurisdicción ordinaria y la propia administración de las resoluciones y actos administrativos que se derivan de las actuaciones policiales en estos centros.

Finalmente, en lo que refiere a su financiación, nuevamente es necesario acudir a sede parlamentaria, concretamente a la Comisión de Interior del Senado, con fecha de 2 de octubre de 2018, en la que el Ministro de Interior Fernando Grande-Marlaska declaró que "el 23 de julio, la Secretaría de Estado aprobó una resolución con carácter de emergencia para la tramitación de diversos expedientes de contratación, con el fin de atender las necesidades de alojamiento y manutención consecuencia de la llegada importante de embarcaciones con migrantes" ${ }^{62}$. Asimismo, en la misma declaración se menciona el acuerdo firmado entre la Secretaria de Estado de Seguridad y la Autoridad Portuaria de la Bahía de Algeciras, por el que se ceden unos terrenos en el término municipal de San Roque para el establecimiento del CATE. En definitiva, si los gastos son sufragados con cargo a las aplicaciones presupuestarias correspondientes al presupuesto de gastos del Servicio Presupuestario de la Dirección General de la Policía y a la sección 16 del Ministerio de Interior (programa 132 seguridad ciudadana), indirectamente se está haciendo una localización orgánica de estos centros dentro de la estructura de la DGP del Ministerio del Interior. Una vez más, la incertidumbre

62 Disponible en www.migrarconderechos.es/legislationMastertable/legislacion/RSES_23_07_2018_ emergencia_contratacion;jsessionid=9346E922CF652E6CAD3A6C1AB5EDD0C6 
de su naturaleza jurídica dificulta su monitorización también desde el punto de vista de la gestión presupuestaria (incluso ante posibles inspecciones de órganos administrativos de control de gasto o Tribunales de Cuentas). Convendría, por tanto, delimitar su ubicación tanto en la jerarquía orgánica de la administración en la que se ubican, así como las competencias y funciones que se le atribuyen.

Por lo tanto, no se trataría de centros autónomos como pudieran ser los CIE o los CETI, sino anexos o extensiones de las comisarías, creados para albergar a detenidos que por su volumen no son recluibles en los calabozos de las propias comisarias. Ahora bien, la duda que aquí surge es si esta decisión responde a criterios de humanidad (evidentemente los nuevos CATE no son almacenes en semi-ruina o cubiertas de barcos a la intemperie) o bien a cuestiones de creación de espacios donde la gestión policial de los desembarcos se realiza de una manera más acorde a las nuevas pautas marcadas en los hotspots italianos y griegos. Tales decisiones, que tan a menudo responden a cuestiones de eficiencia (ejecutar más devoluciones, con menos internamientos o detenciones, al menor coste económico y burocrático) pueden adolecer de falta de fundamento legal o constituir vías de hecho que deben ser controladas tanto por operadores jurídicos como abogados o fiscalía, como por organizaciones sociales encomendadas a esa misión. En el siguiente apartado, miraremos a distintos mecanismos previstos en el ordenamiento jurídico para el control de la actuación pública ante la vulneración de derechos y garantías de las personas recluidas en los CATE.

\section{GARANTÍA DE DERECHOS EN LOS CATE Y MECANISMOS DE CONTROL}

En lo que refiere a la garantía de derechos en los CATE, en tanto que son espacios de detención, debemos prestar atención a varios aspectos. En primer lugar, el relacionado con los derechos inherentes a la persona en situación de custodia policial. En segundo lugar, es importante preservar una situación de dignidad durante la detención, por lo que es fundamental referirse a la situación y arquitectura de los CATE. Finalmente, es imprescindible referirse a los mecanismos de control cuando las garantías son conculcadas.

A pesar de que, en opinión del Ministro del Interior, el objetivo de estos centros es "mantener localizables a las personas, y en ningún caso detenidas", una especie de custodia policial para la identificación, tal y como manifestó 
Antonio de Haro, inspector jefe y responsable de la Unidad Central contra las Redes de Inmigración y Falsedades Documentales (UCRIF) en Málaga en las Jornadas sobre Periodismo de Fronteras de 2019, "las personas una vez son desembarcadas, están en calidad de detenidas" y "tanto la Fiscalía como los juzgados competentes lo entienden así" ${ }^{63}$. Por lo tanto, les corresponden evidentemente los derechos recogidos en el Estatuto del Detenido (el 520 Ley de Enjuiciamiento Criminal o LECrim) y de procedimientos de expulsión/ devolución del art. 22 LOEx como son el derecho a ser informado de forma inmediata, y de modo que le sea comprensible, de sus derechos y de las razones de su detención, el derecho a no declarar contra su voluntad, la garantía (incluso gratuita) a la asistencia de abogado en las diligencias policiales y judiciales, así como el derecho a que se ponga en conocimiento del familiar o persona que desee, su detención y el lugar de custodia, y, fundamentalmente a no llevarse a cabo la devolución en supuestos de solicitud de protección internacional, mujeres embarazadas, menores y personas enfermas. Mirando el caso del CATE de Arguineguín, la mayoría de las personas permanecieron allí varias semanas en una situación de detención totalmente ilegal puesto que el límite para la custodia policial sin actuación judicial que decretara su internamiento en un CIE es de 72 horas. Uno de los fundamentos esgrimidos por la policía y posteriormente recogidos en el Auto judicial del juzgado de instrucción $\mathrm{n}^{\mathrm{o}} 2$ de San Bartolomé de Tirajana, de 23 de noviembre (FJ cuarto), fue que no era posible proceder a la reseña policial hasta la obtención de un test de PCR con resultado negativo. En contra de la realidad confirmada por los migrantes allí detenidos, sus familiares y los abogados que los asistían, según este auto, no se limitó la "libertad ambulatoria" salvo en casos de "una prudente proporcionalidad entre la limitación de dicho derecho fundamental y la salvaguarda de la salud pública".

Merece aquí especial referencia el artículo 520.6.d) LECrim que establece el derecho a entrevistarse reservadamente con el detenido, incluso antes de que se le reciba declaración por la policía, el fiscal o la autoridad judicial", por dos motivos; en primer lugar, como hemos visto, en numerosas ocasiones el Defensor del Pueblo ha reiterado la vulneración del derecho a la entrevista reservada e individualizada; y en segundo lugar, es preciso recordar que desde el mismo momento en que son desembarcados, la policía, pero especialmente Frontex, ya están indagando e interrogando a los migrantes. Es

63 ASOCIACIÓN PRENSA MALAGA Streaming HD Granada 15/3/2019. Disponible en https://youtu.be/ $x$ ViElOZu884?\%20t=549

ISSN: 1133-0937

DOI: https://doi.org/10.20318/dyl.2021.6108
DERECHOS Y LIBERTADES

Número 45, Época II, junio 2021, pp. 267-302 
nuevamente llamativo el caso de Arguineguín, puesto que fueron numerosas las quejas públicas que realizaron los abogados que tenían la designación por turno de oficio del Colegio de abogacía. Además de la ya mencionada denuncia por detención ilícita por superar las 72 horas, también se denunciaron las deplorables condiciones para el ejercicio profesional: asistencias colectivas (cuando deben ser individualizadas y reservadas), "en diferido" (en la comisaría cuando la persona estaba en el puerto a kilómetros de distancia), todo ello previsto en al 520 de la Ley de Enjuiciamiento Criminal ${ }^{64}$.

Con todo, las Comisiones de Extranjería de los Colegios de Abogacía han sido claves, en la garantía de los derechos de los migrantes detenidos en general ${ }^{65}$, y especialmente en la organización de dispositivos específicos para garantizar el derecho a la asistencia letrada en las llegadas a costas, y más recientemente en los CATE. Los Colegios de Cádiz, Málaga, Granada y Almería, entre otros, disponen de protocolos específicos de actuación urgente ante las llegadas de embarcaciones, de manera que existe una coordinación para garantizar la presencia de un abogado por cada 10 o 12 migrantes, así como sistemas de apoyo telemático a través de redes sociales creadas ad hoc (como grupos de whatsapp). Evidentemente, a pesar de que, en el momento del desembarco, las personas están en situación provisional de detención por entrada ilegal por puesto no habilitado, desde el instante en que se invoca el derecho a solicitar protección internacional el status de esa persona cambia, quedando en suspenso el procedimiento de devolución, y abriéndose un itinerario alternativo previsto en la Ley 12/2009, de 30 de octubre, reguladora del derecho de asilo y de la protección subsidiaria.

En lo que refiere al control como recintos públicos, el control de legalidad por parte de operadores externos, principalmente organizaciones sociales, se ha centrado también en aspectos formales. Resulta interesante las acciones de denuncia de la APDHA de Málaga. En primer lugar, recuerdan que el nuevo CATE incumple el acuerdo plenario del 26 de febrero de 2015, alcanzado unánimemente, donde se acordó el rechazo a que, en un futuro, se instalara en su término municipal cualquier tipo de edificio o instalación pública -ya sea bajo la denominación de Centro de Internamiento de Extranjeros, Centros de Estancia Controlada de Extranjeros, Centros de Estancia Temporal o cualquier otra que se pueda utilizar- que tenga como objetivo la privación de libertad e interna-

64 Circular 68/20203 colegio abogados Gran canaria.

65 I. BARBERO, "El acceso a los centros de internamiento para extranjeros como control y garantía de derechos”, Derechos y Libertades, núm. 37, 2017, pp. 233-256. 
miento de personas inmigrantes por el simple hecho de su situación administrativa" (Acta n4/15 de la Comisión de Pleno del Ayuntamiento de Málaga). Así mismo, en lo que refiere a la licitación, la relativa al CATE de Málaga, estando proyectada desde abril de 2018, se realizó por el procedimiento de emergencia cuando, según el artículo 120 de la Ley de Contratos del Sector Público "solo es posible acudir a este procedimiento de contratación de manera excepcional, esto es, cuando hay que realizar una obra de manera inmediata". Finalmente, la APDHA junto con ElDiario.es formularon una queja en torno a la construcción arquitectónica del centro ya que, según la instrucción técnica para el diseño y construcción de áreas de detención 11/2015 de la Secretaría de Estado de Seguridad, la medida media para las celdas colectivas debería ser $4 \mathrm{~m}^{2}$ mínimos por persona, mientras que en el CATE solo se cuenta con $2,3 \mathrm{~m}^{2}$ de espacio de media por persona, pudiendo dar lugar a situaciones hacinamiento. De esta manera, ejerciendo el derecho a intervenir en asuntos públicos en calidad de interesados, las organizaciones sociales no solo intervienen en cuestiones de vulneración de derechos, sino de fiscalización de la actividad de la Administración en labores técnicas (licitaciones, construcción de recintos, contratos...).

Es preciso mencionar los distintos mecanismos previstos en el ordenamiento jurídico para el control y denuncia ante malas praxis y vulneraciones de derechos en estos centros. En primer lugar, debemos decir que, a diferencia de otros contextos cercanos, en España, más allá de denuncias y los recursos ordinarios en vía administrativa y judicial, no existe un mecanismo de queja específico previsto en la Ley de extranjería para los supuestos vulneración de derechos e irregularidades en el control fronterizo y procesos de expulsión $^{66}$. Así mismo, a diferencia de los CIE donde sí está previsto que los internos puedan presentar quejas ante la dirección del centro (Art. 16.n $\mathrm{RCIE}^{67}$ ), que debe ser controlada por el juzgado de control del lugar de ubicación del CIE, debemos entender que si se diera el caso, cualquier persona detenida en un CATE, y que hubiera sufrido algún tipo de vulneración de derechos, estaría legitimada a interponer la correspondiente denuncia ante la fiscalía o ante el juzgado correspondiente, actuación que podría ser llevada a cabo por el o la abogada que le asistiera durante su detención en el

66 I. BARBERO, M. ILLAMOLA, “Deportations without the Right to Complaint: Cases from Spain" en S. CARRERA, M. STEFAN (eds.), Fundamental Rights Challenges in Border Controls and Expulsion of Irregular Immigrants in the European Union Complaint Mechanisms and Access to Justice, Routledge, Londres, 2020.

67 Real Decreto 162/2014, de 14 de marzo, por el que se aprueba el reglamento de funcionamiento y régimen interior de los centros de internamiento de extranjeros.

ISSN: 1133-0937

DOI: https://doi.org/10.20318/dyl.2021.6108
DERECHOS Y LIBERTADES

Número 45, Época II, junio 2021, pp. 267-302 
CATE, a través de la Oficina del Defensor del Pueblo o por parte de alguna organización social.

Debemos referirnos también a las posibles vulneraciones que pudieran cometer los agentes de Frontex presentes en los CATE, quienes, más allá de su dudoso régimen jurídico como agentes policiales (¿Cuál es el estatuto de los agentes de Frontex?¿En calidad de qué están en los CATE?¿Son controlables su actuaciones?), están sometidos a su propia regulación (Reglamento (UE) 2016/1624 del Parlamento Europeo y del Consejo, de 14 de septiembre de 2016, sobre la Guardia Europea de Fronteras y Costas) y al resto de legislación comunitaria en materia de derechos fundamentales, especialmente consagrados en la Carta Europea de Derechos Fundamentales. De hecho, desde 2016, se prevé un mecanismo de queja ante la Oficina de Derechos fundamentales de Frontex, por cualquier afección a derechos generada por agentes de Frontex o de Estados miembros actuando en operaciones relacionadas con la agencia europea (art. 72 Reglamento Frontex). Se tiene constancia de una visita a Andalucía en agosto de 2019 del equipo de la Oficina de Derechos fundamentales de Frontex con el fin de exponer tanto a agentes propios como españoles, así como a ONG, pero según la dirección de tal organismo, hasta la fecha de redacción de este texto no se ha recogido ninguna queja formal en este contexto.

Finalmente, en numerosas ocasiones, se ha debatido a cerca de la capacidad de control de la actuación de la Administración, por parte autoridades como los cargos electos del Parlamento Europeo, las Cortes generales o Parlamentos autonómicos. Al igual que en los casos de centros penitenciarios, comisarias, CIE, CETI y otros centros de privación de libertad, se ha defendido la necesidad de que sea un control inmediato (sin cita ni aviso previo) y pleno (a todos los lugares) para garantizar una fiscalización efectiva y veraz de la situación real ${ }^{68}$, y no como defendía el Ministro del Interior en el contexto de una sesión de control parlamentario, con comunicación previa "por cuestiones organizativas" (Senado, 2 de octubre de 2018) ${ }^{69}$. Sin embargo, este derecho parlamentario se ha visto conculcado tanto en noviembre de 2020 cuando el diputado Jon Iñarritu no pudo acceder al CATE de Arguineguín cómo el día 4 de diciembre del 2020 cuando varios europarlamentarios (Miguel Urban,

68 I. BARBERO, El acceso a los centros de internamiento para extranjeros como control y garantía de derechos", cit., pp. 233-256.

69 Comparecencia ante el Senado del Ministro del Interior, D. Fernando GrandeMarlaska Gómez, ante la Comisión de Interior, para informar sobre las líneas generales de la política de su Departamento, 2 de octubre de 2018. Disponible en $h t t p: / / w w w . s e n a d o . e s / l e g i s 12 /$ publicaciones/pdf/senado/ds/DS_C_12_327.PDF 
Malin Björk y Pernando Barrena, de grupo GUE/NGL), un parlamentario del Parlament catalán, Rubén Wagensberg y, de nuevo, Jon Iñarritu, intentaron acceder al CATE de Barranco Seco. Iñarritu finalmente pudo acceder, previa autorización de Interior el 30 de enero de 2021.

Además, es necesario referirse a la posibilidad de que organizaciones no gubernamentales accedan a los CATE, no solo como prestadoras de servicios, sino para realizar acciones de monitoreo de la actividad de la Administración. El artículo 62 bis de la actual Ley de Extranjería, en consonancia con el mandato de la Directiva 2008/115/CE relativa al retorno (art 16.4), recoge tanto el derecho del interno en CIE a entrar en contacto con organizaciones no gubernamentales y organismos nacionales, internacionales y no gubernamentales de protección de inmigrantes (art 62 bis 1. j); como el derecho de las organizaciones constituidas legalmente en España para la defensa de los inmigrantes y los organismos internacionales pertinentes a visitar los centros de internamiento (62 bis 3). En el caso de los CATE, al no haber una regulación específica, el acceso de organizaciones no gubernamentales queda sujeta a la decisión discrecional del Ministerio del Interior o inferior jerárquico. Así, como ya hemos mencionado en este artículo, la organización Cruz Roja, a través de un convenio de adjudicación directa con el Ministerio de Interior (similar al previsto para los CIE), realiza tareas ERIE (Equipo de Respuesta Inmediata en Emergencia), asistencia médica (triaje y seguimiento) y social (manutención y reubicación tras la puesta en libertad). De una manera similar a los hotspots italianos y griegos donde está presente EASO, en el caso español el Alto Comisionado de las Naciones Unidas para el Refugiado (ACNUR) quien está presente en los CATE a través de personal de CEAR, para ofrecer información y asistencia en materia de asilo en los CATE (junto con los turnos de abogacía). Por lo tanto, son solo estas las organizaciones que cotidianamente acceden a los CATE, sin que otra organización pueda acceder de manera formal (profesionales de prensa, en ocasiones imprescindibles para conocer lo que sucede en los CATE, sólo pueden acceder con la debida acreditación).

En suma, al tratarse de centros donde la situación de detención se produce en unas circunstancias tan extremas y donde las personas pueden presentar múltiples vulnerabilidades, es evidente que, ante una hipotética regulación, y siguiendo los mandatos de instituciones y normativas comunitarias, desde una lógica de garantía de los derechos fundamentales de las personas detenidas (incluso para preservar y fomentar buenas prácticas por parte de funcionarios y personal adscrito a los centros) deberían articularse mecanis- 
mos de control y queja; así como vías para que órganos públicos de control y organizaciones independientes tengan un acceso mayor a las instalaciones, a la información relativa a la toma de decisiones referentes a estos centros y a la personas en ellos custodiadas, para evitar situaciones en las que la legalidad de éstas decisiones quede en entredicho.

\section{CONCLUSIONES}

A pesar de la ausencia total de una regulación de rango legal que prevea la existencia de los CATE, y mucho menos, una norma de rango reglamentario que los desarrolle, no cabe duda de la existencia y su reconocimiento por parte de instancias gubernativas como espacios de detención ante las llegadas a costas. Más de 50.000 personas, incluidas menores han pasado por alguna de las distintas modalidades de CATE que han existido en los últimos años, y nada apunta (ninguna declaración política hasta la fecha) a que vayan a desaparecer, especialmente ante la persistente llegada y rescate de embarcaciones a costas. Las políticas de externalización de fronteras con Marruecos, Senegal, Mauritania o Argelia, lejos de frenar en seco las salidas, no hacen sino (re)activar rutas peligrosas y desembocar en naufragios, muertes y desapariciones en aguas del Atlántico y del Mediterráneo. En ese sentido, será más necesaria una gestión humanitaria que policial.

Como apuntábamos anteriormente, resulta interesante la desaparición de la palabra "detención" que recogía la denominación inicial. No responde sino a una estrategia de maquillaje o camuflaje de estos centros dentro de la lógica de humanitarización del control fronterizo. Frente a los CIE que son centros de inspiración penitenciaria, los CATE en ocasiones se presentan como espacios asistenciales. El encaje de estos centros en esta lógica humanitaria a la que se refería Walters la encontramos con la presencia de organizaciones publico/ privadas Salvamento Marítimo, de organizaciones no gubernamentales como Cruz Roja, Save the Children o CEAR/ACNUR o instituciones como los colegios de abogacía, prestando servicios médicos/ asistenciales y de asesoría. Al igual que se justifica el empleo de tecnología de vigilancia para evitar riesgos, daños, crímenes o muertes de las personas que tratan de cruzar las fronteras, se recurre a las organizaciones sociales para atender a víctimas de las inclemencias climáticas o la dureza del trayecto por el mar. Concretamente, la presencia de personas especialmente vulnerables como mujeres víctimas de trata, demandantes de protección internacional 
o de menores (acompañados y no acompañados) en espacios altamente policializados choca con toda lógica de preservación del interés superior del menor, por lo que deberían buscarse alternativas más allá de la separación en módulos dentro de los CATE, como podrían ser centros para familias.

La principal diferencia de los CATE con los centros denominados hotspots ubicados en Grecia e Italia, es que éstos últimos están formalmente reconocidos por las instituciones comunitarias como tales, derivando su régimen jurídico por tanto de normativa comunitaria. En el caso español, el único anclaje con la Unión Europea sería la presencia de agentes Frontex y la obligatoria reseña en bases de datos comunitarias como EURODAC. Además, a diferencia de los hotspot donde el compromiso de reubicación era una de las notas definitorias, en el caso español se optó por un improvisado laissez passer hacia países del norte europeo, dando lugar a la desatención de esas personas, así como a una gestión férrea de control fronterizo interno por parte de Francia, y que a posteriori está dando lugar a devoluciones a España de personas que solicitaron asilo en Francia, Bélgica o Alemania, en aplicación del Reglamento de Dublín. Con todo, no debemos olvidar que existe una regulación comunitaria, ya sea la Directiva de Retorno como la prevista de procedimientos de asilo, y más especialmente, la Carta de Derechos fundamentales, que pueden constituir un límite a actuaciones totalmente reprobables por parte de los agentes policiales encargados de la custodia y gestión de esos centros, incluidos los agentes de Frontex los cuales podrían ser controlados a través del mecanismo específico de la Oficina de Derechos Fundamentales de la propia agencia europea.

Por lo tanto, de la interpretación de preguntas parlamentarias y resoluciones administrativas podemos decir que se trataría de dispositivos de contención vinculados o anexados a comisarías cuyo fin único es agilizar las labores policiales de identificación y derivación (CIE, devolución...), evitando, por un lado, la burocracia administrativa y judicial que supone el internamiento en CIE; y por otro, la sobreocupación que han presentado CIE como Algeciras en momentos puntuales. Debemos enmarcar, por tanto, estos centros dentro de la nueva gestión gerencial del control migratorio en la medida que su fin es limitarse a cumplir el objetivo de gestionar la llegada y seleccionar el destino de cada una de las personas atendiendo a circunstancias personales como la nacionalidad. Las decisiones puntuales sobre el destino de las personas se toman tendiendo a parámetros de eficiencia policial como la (in)expulsabilidad de determinados orígenes o las tasas de ocupación de los CATE. 
Con todo, es importante señalar que las posibles mejoras de las instalaciones (ventilación, espacios comunes, baños y duchas...) así como el reconocimiento y garantía de derechos (asistencia letrada, información sobre protección internacional, etc.), no debe limitarse al enfoque gerencial-humanitario, sino que es fruto de la presión ejercida por instituciones garantistas como el Defensor del Pueblo o las Comisiones de Extranjería de los Colegios de Abogacía (incluso trabajadores de Salvamento Marítimo), así como de organizaciones sociales como APDHA, CIEs NO o ACNUR que han vigilado la labor de la Administración y han planteado denuncias ante instancias administrativas y judiciales y ante los medios.

Concluimos diciendo que lo ideal sería que no existieran los CATE para la reseña policial, sino verdaderos centros de recepción humanitaria con instalaciones de acogida para personas vulnerables rescatadas en situaciones dramáticas. Mientras tanto, es una demanda social y un requisito legal que se regulen a través de normas de rango legal (incluso por ley orgánica, puesto que afectan directamente a los derechos fundamentales de las personas ahí detenidas), que posteriormente sean desarrolladas tras un proceso de recogida de propuestas de entidades sociales y expertos en materia de derechos y garantías. Así mismo, es indispensable que esa regulación recoja mecanismos de queja ante vulneración y permita el acceso de organizaciones sociales para la prestación de servicios, así como para la garantía de los derechos y control de las instituciones, puesto supondría el cumplimiento de mínimos que toda sociedad democrática merece. Finalmente, es imprescindible concluir recordando que, tal y como ya recomendó el Defensor del Pueblo al Ministerio del Interior (Recomendación del 24 de julio de 2018) una vez constatada la inexpulsabilidad de la persona, sería de justicia proveer de un documento acreditativo de su situación de manera que no sean objeto de procedimientos policiales ni lesivos ni privativos de libertad, o incluso promover un procedimiento de regularización circunstancial de manera que cientos de personas no queden en un limbo jurídico que les avoque a la exclusión.

IKER BARBERO Universidad del País Vasco/Euskal Herriko Unibertsitatea. Departamento de Derecho Administrativo, Constitucional y Filosofía del Derecho. Campus Sarriko, 48015 Bilbao e-mail:iker.barbero@ehu.eus 